\title{
Mobile 'green' design knowledge: Institutions, bricolage and the relational production of embedded sustainable building designs
}

James R Faulconbridge

Lancaster University, UK

Email: j.faulconbridge@lancaster.ac.uk

Please cite as: Faulconbridge JR (2013) Mobile 'green' design knowledge: Institutions, bricolage and the relational production of embedded sustainable building designs. Transactions of the Institute of British Geographers 38 (2) 339-353 


\begin{abstract}
Buildings are responsible for on average $43 \%$ of anthropogenic carbon dioxide emissions, a figure that can rise to $70 \%$ in cities. Consequently, 'green' building design has been focussed on in efforts to reduce environmental degradation and change. It has been suggested, however, that collective learning and the mobilisation of knowledge between spatially dispersed communities are urgently needed, in particular to overcome what are often portrayed as knowledge deficits in relation to green design. The remit of this paper is to outline a framework for analysing the geographically heterogeneous impacts of attempts to mobilise green design knowledges. Drawing on economic geographical analyses of knowledge mobility, the paper reveals how regulative, normative and cultural-cognitive institutional contexts render green building design knowledges situated and place specific. But it is also shown that bricolage - the bringing together of multiple mobile knowledges to produce new embedded green design knowledges can overcome some of the problems faced. In particular the analysis developed in the paper reveals: first, the role of multiple topological connections to metrically near and far but institutionally proximate places in providing diverse knowledges that can be folded together into place specific solutions, and hence the need to conceptualise knowledge mobility as involving plural geographies of flow from multiple cities in the global north and south; second, the way economic geographers can contribute to debates about transitions to sustainability and situated sustainable building design through institutional analyses of the topologies of knowledge mobility, thus widening the relevance of their work to debates about the environment and climate change.
\end{abstract}

Keywords: Sustainable buildings; green design; institutions; knowledge; mobility; interviews 


\section{Introduction}

This paper analyses an important trend relating to sustainable buildings: the mobilisation across space, between communities, cities, regions and countries, of 'green' (i.e., negative environmental impact mitigating) building design knowledges. Recent years have seen a proliferation of schemes designed to inspire the sharing of green building design 'best practices'. Examples include: the UN's "Design for Sustainability" plan (UNEP, 2006) and specifically in relation to buildings its 'Action Plan for Energy Efficiency' which seeks 'to develop and implement projects of common interest on crosscutting issues that would assist governments in improving energy efficiency' (see http://www.unece.org/energy/se/eneffic.html); the work of the World Green Buildings Council and its 'six continents, one mission' strategy, the mission being to accelerate the transformation of buildings towards sustainability through international collaboration, something aided by the launch of World Green Buildings Day in 2009 (see World Green Building Council, 2009) and; the Large Cities Climate Leadership Group (see http://live.c40cities.org) and their provision of both best practice case studies and forums in which city planners can network and share expertise. Other groups as diverse as the European Union, professional associations allied to the building industry, and manufactures of sustainability technologies have all in various ways also begun to prioritise the mobilisation of knowledge as a mechanism for driving transitions to sustainability. And in addition, global architects (McNeill, 2008) alongside various global property development and consultancy firms allied to the building design industry (Olds, 2001) have also been powerful economic agents in this mobilisation process, using their inter-office knowledge communities (Faulconbridge, 2010) and their involvement in projects worldwide (Faulconbridge, 2009) to import best practices into new geographical contexts. 
The recent proliferation of efforts to mobilise green building design knowledges has been driven by two factors. First, the environmental impact of buildings has gained significant attention in both public policy and industry circles. This is unsurprising given the fact that buildings, including everything from domestic dwellings to city skyscrapers, are said to be responsible for on average $43 \%$ of anthropogenic carbon dioxide emissions (Brown and Southworth, 2008), a figure that can rise to $70 \%$ in cities (City of London, 2008). The main cause of emissions is the use of electricity and gas for heating and cooling. Consumption in buildings for everything from drinking to flushing toilets and watering plants also places a major strain on increasingly scarce water supplies, whilst resource exploitation during construction and waste production during demolition only further compound the environmental footprint of buildings. Hence, finding a way to reduce the environmental impact of buildings has become a priority with mobile knowledges being seen as one potential source of solutions. Second, recourse to mobile knowledges is also explained by the fact that, in the eyes of many policy makers, attempts to reduce the environmental impact of buildings are currently impeded by the fact that expertise is overly concentrated in a few social (e.g. particular communities of design professionals) and geographical arenas (particular places) and the benefits of collective learning and the sharing of green design knowledges are not often enough realised. The Academy for Sustainable Communities (2007) bemoans the fact that "many of these professions [involved in sustainable design] face acute recruitment shortages and in several activity areas there is a lack of essential generic skills". Meanwhile, the UK's National House Building Council Foundation argues that "there is an obvious need to learn key lessons from overseas. While every country has unique domestic circumstances, this Compendium urges us not to reinvent the wheel or ignore critical 
insights which have been gained over time" (NHBC Foundation, 2009: 1). And as such, the rationale behind the mobilisation of knowledges can be explained by an underlying logic that mirrors that of previously documented attempts to develop networks of 'best practice' relating to sustainable cities more broadly (on which see Bulkeley, 2005, 2006): knowledge deficit issues can be resolved by encouraging building designers to learn from colleagues located in different social and geographical spaces. The question this raises is how to better understand what influences the impacts of such knowledge mobilisation?

To address this question, the current paper focuses empirically on the mobilisation of knowledge relating to green design issues in commercial, public sector and mixed-use buildings in cities. This focus is in some ways rather narrow as it ignores many other debates about the sustainable building concept (for a summary see Guy and Moore, 2007); a concept which can relate to everything from environmental impact, the focus here, to the building's role in the generation of high quality jobs. The focus also leads to the exclusion of many other building forms, in particular domestic dwellings which are as if not more important in terms of sustainability. Whilst these blind-spots are not insignificant, the chosen case study remains valuable because it provides an empirical lens through which to develop conceptual insights relevant to other building types and to more than just the green issues associated with sustainable buildings. Specifically, the chosen case study generates rich empirical insights that focussing on other sustainability issues or other building forms may not; these insights emerging because of the intensity of green knowledge mobilisation efforts in relation to commercial, public sector and mixed use buildings in cities, an intensity generated both by the handsome profits that can be 
made from designing these types of green buildings, and by the focus on cities in public policy strategies targeting sustainability generally and buildings in particular.

To build its conceptual contribution, the paper draws on economic geographers' work on knowledge mobility, and in particular the institutional dimensions of this mobility (for summaries see McCann and Ward, 2011; Peck and Theodore, 2010), and work on cities as relational assemblages (Allen and Cochrane, 2007; Massey, 2005) to analyse how the institutional embeddedness of green building design plays a central role in determining the usefulness and effects of mobile knowledges. The paper's broad argument is that institutional influences on socio-economic challenges such as sustainability generate significant spatial heterogeneity in both the problems faced and the characteristics of appropriate solutions. However, heterogeneity should be seen not as a reason for avoiding the mobilisation of knowledge, but as a spur for the creative use of mobile knowledges to generate new situated solutions and practices through experimentation and hybridisation. This leads, at one level and most straightforwardly, to the contention that an institutional analysis (for summaries of the key tenets of such an analysis see Gertler, 2010) can reveal the interacting multi-level socio-technical factors that render building designs context specific. Consequently, the approach developed here can complement and move forward existing studies of the regulatory (Imrie, 2007) and sociocultural (Jacobs, 2006; Lees, 2001) production of situated built forms and sustainability challenges (Hitchings, 2010; Whitehead, 2007). At a second level, the discussion adds depth to theories of knowledge mobilisation which, to date, have tended to have "deeply embedded assumptions about creativity and mimicry... and about the trajectory of learning” (Robinson, 2011: 22). Specifically, the paper develops a different way of thinking about knowledge 
mobilisation, its spatiality and potentiality (positive and negative) by focusing less on the travels from place to place of a single knowledge practice, and more on the topological intersections of multiple mobilising knowledges that are assembled in any city, something which results in new and embedded knowledges emerging. This perspective emphasises the importance of plural relationalities and diverse geographies of knowledge mobility that can help produce solutions capable of responding to the spatial heterogeneity associated with challenges such as sustainability. At a third level, the framing developed in this paper is important because it shows how economic geographical work on knowledge mobility can be positioned at the fulcrum of debates about sustainability. Some progress has been made in rectifying the initial tardiness of economic geographers in applying their toolkits to what is arguably the pressing social science research agenda of the twenty first century, for example through analysis of how economic geographical perspectives can be used to frame conceptualisations of adaptation (Gibbs, 2006), the role of markets in carbon management (Bumpus and Liverman, 2008), and the environmental impacts of transnational corporations (Dicken, 2011). The analysis presented here develops this line of thinking by using insights from institutional perspectives on knowledge mobility to understand both the causes of geographically heterogeneous practices of and barriers to sustainability, and the role of mobile knowledges in overcoming these barriers. Two examples are given of why such economic geographical analysis of sustainability is valuable, one relating to the contributions that can be made to work on sustainability transitions (see Geels, 2004, 2010; Truffer, 2008), and one relating to work on green building design (see Cole and Lorch, 2003; Guy and Moore, 2007). 
The rest of the paper develops these arguments over four further sections. The next section examines how existing studies of knowledge mobility can be used to interpret the growing role of mobile knowledges in addressing green design challenges. The following two sections then use interview data to examine the multi-dimensional influences of institutions on buildings and the way the institutionally situated nature of green design is responded to by those using mobilised knowledges are sources of solutions. Bricolage is identified as a means of overcoming institutional limitations to the usefulness of mobile knowledges, bricolage being a way of generating new, context-specific and embedded solutions from mobile knowledges. The conclusion section of the paper reflects on the new ways of thinking developed in the paper about knowledge mobility, sustainability and building design and the further questions raised by the analysis.

\section{Mobilising green building design knowledge - a geographical perspective}

Green design knowledges that are mobilised are often drawn from showcase projects that gain notoriety because of structural approaches to green design, for example using the layout of a building to maximise natural light and ventilation, and/or because of the use of increasingly ubiquitous green technologies such as solar voltaics. For instance, London’s ‘Gherkin’ (30 St. Mary Axe, the Swiss RE building) has become infamous for its use (and the misuse) of natural ventilation through opening windows, whilst the Bahrain Word Trade Centre overtly exemplifies the use of wind power technologies. Buildings whose designs are mobilised are also important, however, because they provide insights into how to approach green building innovation in a situated way depending on the impact of particular institutional influences on design. Insights 
provided by mobilised buildings in this regard relate to both the challenge of adhering to regulations and formal requirements in terms of a building's performance, and the complexities associated with convincing owners and occupiers to consider and invest in green design features. I return to these two interrelated dimensions of the insights gained from mobile knowledges in the analysis in the second half of the paper.

Existing studies of communities of practice (Amin and Cohendet, 2004; Bathelt et al., 2004; Faulconbridge, 2006, 2010; Grabher, 2001), global networks of policy learning (Dolowitz and Marsh, 2000), and 'urban policy mobilities' (McCann, 2004; Peck and Theodore, 2001; Ward, 2006) provide useful ways of beginning to analyse the nature and effects of the mobilisation of green building design knowledges. In this literature, mobilisation is taken to mean the circulation of knowledge embodied in best practice case studies, policy models or advice between communities of practitioners who are socially proximate - for example sharing a common interest in building design - but spatially dispersed - for example located in different cities or countries. Three contributions are made to understanding of the way knowledge moves across space by this work. First, the vectors of mobilisation are identified. Policy networks/mobilities studies show that knowledge is mobilised by consultants but also by conferences and as a result of study trips involving delegations sent to visit cities that represent best practice in governance (Dolowitz and Marsh, 2000; McCann, in press). Studies of communities of practice reveal a subtly different process of mobilisation, focussing on the role of interactions between spatially dispersed individuals and communities that allow the sharing of insights and the negotiation of new meanings and understandings in relation to a particular problem or practice. Interactions between community members are facilitated by virtual communication technologies like 
videoconference (Faulconbridge, 2006) as well as by business travel (Faulconbridge et al., 2009) and forms of temporary proximity such as trade fairs (Bathelt and Schuldt, 2007).

Secondly, existing literatures identify the impacts of knowledge mobilisation. Benefits are assumed to accrue from the fact that "individuals and/or organisations will be able to undertake similar projects or processes, or learn from the experience" (Bulkeley, 2006, 1032), something that means knowledge mobilisation connects islands of expertise (Amin and Cohendet, 1999) and allows the leveraging across space of knowledge that can generate economic, environmental, social and other benefits. Such ideas are developed further by Bathelt et al. (2004) through reference to the importance of both 'buzz and pipelines' in contemporary innovation processes, a perspective which attempts to replace dichotomies between local and global, tacit and explicit knowledge with conceptualisations of relational, topological networks of innovation and learning (Allen and Cochrane, 2007; Grabher, 2001).

Thirdly, and counter-balancing any unbridled celebration of knowledge mobilisation, existing studies also raise a number of critical questions about the hurdles to and costs of mobilisation. Particularly important is work that explores the way mobilising knowledges interact with geographically heterogeneous institutional contexts (Gertler, 2001; Storper and Venables, 2004). Existing studies define institutions as both formal rules and regulations set by recognised authorities in a particular institutional field, and the informal norms, customs and traditions that support and result from formal rules (Martin, 2000; Gertler, 2010). Together these two dimensions of institutions are said to influence the priorities, behaviours and decision making of 
actors. Or as Gertler (2004: 7-8) puts it, institutions "define the system of rules that shape the attitudes, values, and expectations of individuals economic actors... These actors may or may not be conscious of the fact that they espouse and are motivated by these attitudes and values, conventions and habits". Two interrelated points have been made about the influence of institutions on the mobilisation of knowledge. First, Gertler $(2001,2004)$ through a series of interventions shows that all knowledges are indelibly marked by the institutional contexts of the spaces they originate in, spaces being defined as communities, cities, regions, countries or combinations of all four. As a result, knowledge developed in one space in relation to a particular challenge - whether it is designing sustainable buildings or effective public policy frameworks is often inappropriate, non-sensical or difficult to implement when imported into the alien institutional space. Relatedly, second, it has been shown that institutional difference leads to communities of practice and policy networks being used to facilitate learning from, and the adaptation of existing knowledges and practices rather than their intact circulation and reproduction (Faulconbridge, 2006; Vallance, 2011). As Peck and Theodore (2010: 170) note, “mobile policies rarely travel as complete 'packages', they move in bits and pieces... and they therefore 'arrive' not as replicas but as policies already-in-transformation... high rates of policy mobility are not a prelude to one-best-way unification, or some sort of policy monopoly". Consequently, knowledge mobilisation has unpredictable and in some cases potentially problematic outcomes when transformations as part of re-embedding processes lead to unintended effects.

Initial steps have been taken towards deploying work on knowledge mobility and institutions to study building design by using the communities of practice framework and studies of 
embeddedness to reveal the way global architects circulate knowledges between worldwide offices, learn from their competitors, and produce design innovations suited to local contexts (Faulconbridge, 2009, 2010). Arguments about the 'local' institutional fixes of design knowledges are also made by several authors in an Urban Studies (2009) special issue of design regulation, whilst D'Arcy and Keogh (1997) show how the institutionally shaped priorities of planning officials, architects, engineers and builders (referred to collectively as building professionals from hereon in), real estate investors including pension funds (referred to as building speculators), and occupiers, all contribute to the production of context-specific understandings of building design. These understandings relate to everything from return on investment expectations of particular communities (van Bueren and Priemus, 2002), to fundamental issues of building design such as the size and shape of floor plates (Willis, 1995), the materials used in construction (Lovell and Smith, 2010) and the role of building codes in mandating or not standards of performance (Imrie, 2007; Urban Studies, 2009). Yet, despite work highlighting sustainable building design as an important focus for empirical analysis (e.g. Cidell, 2009; Hitchings, 2010; Whitehead, 2007), questions about the way mobile knowledges can be used to overcome sustainability design challenges in locally relevant ways and about how institutional difference generates opportunities for and/or barriers to innovation using mobile knowledge have received limited attention. Instead, debates have been dominated by the assumption that knowledge mobility leads to the homogenisation of design practices (for summaries see Cole and Lorsch, 2003; Evans, 2004; Faulconbridge, 2009) and the destruction of vernacular (on the limitations this debate creates see King, 1984). 
In the rest of the paper I, therefore, seek to more systematically investigate what studies of architecture and sustainability can learn from an institutional perspective on knowledge mobility, and in turn what studying the mobility of green building design knowledges might also do to advance the economic geographical work on knowledge outlined above. The analysis presented draws on institutional theory not only from economic geography but also from sociology and management. The management and sociology brand of institutional theory used pays particular attention to the way institutions are comprised of what Scott (2008) refers to as three pillars. The regulative pillar relates to rules that compel particular actions or behaviours - e.g. building codes. The normative pillar relates to social obligations and norms of appropriateness - e.g. whether a building should be air conditioned. The cultural-cognitive pillar relates to taken-forgranted logics that guide approaches to a task - e.g. the logic that questions about building design should be interpreted through a lens which helps maximise return on investment for the owner. By adopting Scott's work on the three distinct yet interactional pillars of institutions, a multi-dimensional explanation of the situated influences on approaches to building design is developed and the way these influences determine the role of mobile knowledges in addressing green design challenges revealed. In particular, the analysis is able to overcome the tendency in existing economic geographical literatures on knowledge mobility to focus predominantly on how the formal regulatory dimensions of institutions lead to mobile knowledges being transformed at the expense of analysis of the effects of the more informal-normative and cultural-cognitive pillars.

Overall, the analysis presented suggests that discussions in existing literatures of the institutional barriers to knowledge mobility (Gertler, 2004), the problems that may arise when re-embedded 
knowledges mutate (Peck and Theodore, 2010), and the risks of convergence and homogeneity in practice (Cole and Lorsch, 2003) need complementing with an alternative perspective that considers the opportunities generated by institutional diversity for experimentation and innovation. This alternative perspective emphasises the way that institutional difference generates plural practices and solutions to socio-economic challenges such as sustainability, practices and solutions that when mobilised and most importantly synthesised as part of responses to challenges in a different community, city, region or country can together generate new innovative knowledges that form the basis of contingently effective, locally sensitive practices. Hence the transnational relational assemblages that so often define cities can reproduce rather than erode geographical diversity when put to work in appropriate ways, and produce novel local solutions that can be made to have also global relevance when themselves mobilised and re-embedded in new contexts.

\section{Methodology}

The analysis below is built upon empirical material collected through, first, a series of semistructured interviews conducted in 2009 with a range of actors involved in the design of public sector, commercial or mixed use buildings in cities and, second, a review of relevant academic and practitioner literatures. Twenty five interviews were conducted with: architects (10 interviews); building engineers (3); property developers (3), green building design consultants (4), members of green building associations (2), and professional bodies representing all of the aforementioned actors (3). Interviewees were based in either the UK (10) or Australia (15), all had to varying degrees experience of working outside of their country of residence, and in many 
cases worked for global organisations. All interviewees were chosen as key informants because of their central role in sustainable design in their firm or profession. For example, they held titles such as 'head of sustainability', 'sustainability consultant' or worked for an organization that had sustainable design as its remit. The two countries were chosen as the location for interviews because building professionals in both have increasingly prioritised green design, in the case of Australia particularly in response to challenges associated with water shortages and temperature extremes, in the case of the UK as part of attempts to meet government targets to reduce carbon dioxide emissions. Consequently, interviewees had all sought knowledge relating to green design from overseas colleagues, firms, publications and conferences. The focus of the analysis is not, however, on Australia and the UK as case study countries. Rather it is on insights gained from interviewees into the way mobile knowledges get appropriated and implemented and the institutional determinants of this. Consequently, examples given of the effects of institutional context on mobile knowledges are drawn from several countries and social communities in which the interviewees had worked, including but not limited to the UK and Australia.

Interviews, which lasted between 35 and 90 minutes, focused on green building design and: its definitions; its regulation; the situatedness of approaches of building professionals, speculators, and occupiers; and the role and usefulness of mobilising knowledges in addressing key challenges. All interviews were recorded and transcribed. Transcripts were coded thematically and code tables used to identify connections between interview data, debates and discussions in practitioner magazines and journals (e.g. Building Design; The Architect's Journal), and academic work on institutions, knowledge mobility and architecture. Throughout the analysis 
sections of the paper anonymous quotations are used to illustrate the key connections identified and support the arguments developed.

\section{Institutional influences on green building design}

Table I summarises the mechanisms that allow green design knowledges to travel. It reveals that a range of actors are involved in the mobilisation of knowledge, with actors all having their own political-economic motivations for disseminating knowledges. Because the aim of this paper is not to unpick the way circulation itself occurs, a more detailed analysis of the mechanisms by which knowledges travel is not provided here. As already noted, others (Bathelt et al., 2004; Bathelt and Schultz, 2004; Faulconbridge, 2006, 2010; Grabher, 2001; McCann, 2004, in press; Peck and Theodore, 2001; Ward, 2006) have provided extensive discussion of such issues and the ideas outlined in the literature review about the social processes of learning in communities of practice (via face-to-face and virtual interactions) and the role of policy networks/mobilities for allowing best practice to circulate (travelling technocrats, conferences, study tours) can all be applied directly to the case of green building design. In the rest of the paper focus falls instead on the third institutional issue flagged in the literature review; as one interviewee put it, the way mobilising knowledges require "adaption to the local context... We're always on the lookout for what seems to be interesting overseas and how we can adapt it here" (18, Architect, Australian practice, emphasis added). This issue is explored through Scott's (2008) three pillars framework because it highlights how mobilised knowledges interact in complex multi-dimensional ways with situated institutional regimes.

[Insert Table I here] 
The regulative, normative and cultural-cognitive dimensions of green design

The regulative dimension of institutions has both a direct and indirect effect on buildings and approaches to green design. The direct effect relates to geographical heterogeneity in building codes (on which see Imrie, 2007). Heterogeneity exists between countries, and also at the subnational scale. For instance, in Australia, as in the USA, different state-level regulations exist as regards the environmental performance of buildings. In New South Wales, BASIX (the Building Sustainability Index), introduced in 2004, requires that all new homes include design features which reduce water and energy consumption. In contrast a number of other Australian states have no or different regulatory regimes. The impact of such heterogeneity in codes on buildings and mobilising knowledges was described by one design manager working in Sydney as follows:

"You go down to Melbourne the power is generally brown coal, so it's very high carbon...So cogen [co-generation of electricity for multiple buildings within a development] seems to be favoured in Melbourne because of those issues. So you do get slightly different outcomes...So I think if you picked this building up [an exemplar of sustainability in Sydney scoring five stars in a recent assessment] and plonked it down in Canberra it could only be four star. You end up with slightly different answers for different places" (19, Australian head of design, global property development firm).

The result of the direct effects of the regulatory pillar is, then, to render some mobilising knowledges illegitimate when transferred to new institutional contexts - i.e., deemed inappropriate or less valuable in the eyes of building regulators in the context of their green 
priorities, or simply prohibited in the context of rules and regulations; a combination of both forms of illegitimacy leading the interviewee quoted above to suggest a building would receive a different grading of its green credentials in different states within Australia. And, the regulative dimension has further indirect effects that create additional impediments to knowledge mobilisation.

Illustrating the indirect effect of the regulative pillar is the case of the refurbishment of buildings to lower energy and water consumption; a vital part of green design strategies. Specifically, past urban planning regimes and their effects on inherited building stocks (on which see D'Arcy and Keogh, 1997) render green refurbishment solutions context-specific. For example, in relation to commercial office space, Willis (1995) shows that the design on New York City's skyscraper building stock has been heavily influenced by a combination of not only by mid-twentieth century developer demands for maximum return on investment, demands often higher in New York City (above ten percent) than other comparable cities (usually around nine percent), but also mid-twentieth century urban planning regulations associated with the 'zoning envelope'. Zoning envelope principles were in part designed to maintain agreeable conditions for pedestrians and dictated that tall buildings must not excessively reduce levels of natural light at ground level. The 'wedding cake' skyscraper design, exemplified most iconically by the Empire State Building, thus emerged because it met the priorities of both market (return on investment) and planning (zoning envelope) institutions by allowing maximum floor space (through large floor plates at lower levels) and high levels of natural light for pedestrians (enabled by narrower floor plates at higher levels). In terms of the implications for knowledges relating to green design, this New York skyscraper specific structure has a significant effect on the organisation of 
key energy consuming services and also effects the amount of natural light and heat a building is exposed to. As Willis (1995: 79) puts it, this example shows how 'finance dictates fenestration' with large floor plates, often in excess of 2000 meters square at the lower levels of wedding cake structure buildings, requiring heating, cooling and lighting systems designed to cope with chasmlike, dark and heat retaining spaces and unique airflows generated by the narrowing floor plates at higher levels; challenges that do not exist in many other buildings in New York and in skyscrapers in other cities.

The existence of such unique challenges in New York City means that distinctive design communities emerge, with the approaches to green design developed in communities focussed on refurbishing wedding cake skyscrapers being less relevant to other communities; for example those refurbishing skyscrapers in another city where buildings were not designed using the wedding cake style, or even those working on non-wedding cake design office space in New York. Hence knowledges do not necessarily travel particularly well between spaces, meaning that although refurbishment has recently begun of the Empire State Building with the aim of reducing energy consumption by 40 percent and making the building an icon of green design (see Pilkington, 2010), in reality the challenges being addressed are in many ways unique to New York and the city's wedding cake skyscrapers. And, it is not just these regulative institutional effects that render green design challenges context-specific.

The normative dimension of institutions determines what, as a result of political-economic context, is deemed socially legitimate and expected, in particular, by occupiers in terms of a 
building's design, facilities and internal spatial layout. One of the most notable examples interviewees gave of this relates to hospital design. Variations in design between public and private healthcare provision exist because of patients' normative expectations about service standards. Public health care systems tend to lead to hospital operators demanding designs that incorporate large communal wards that are relatively cost efficient, reflecting the fact that patient expectations render such accommodation legitimate, if not liked. In contrast, in private systems hospital operators demand designs that allow individual rooms for patients, reflecting expectations that the subscriptions paid ensure an almost hotel-like service. In terms of green design challenges, differences in layouts between public and private funded systems are significant in two ways. First, the distinctive layouts effect the way air circulates, with each requiring a different solution as part of attempts to reduce energy used for heating and cooling. In the case of public hospitals, large communal wards may stretch from one side of the building to another and have multiple windows. This means cross-flows of air are enhanced and can reduce the need for mechanical cooling. In contrast, in private hospitals many private rooms fragment space within the building. Hence cross-flows of air are reduced and, therefore, technologies that minimise the electricity consumption of mechanical ventilation systems are often a more realistic way to render the building less environmentally harmful. In addition, second, the different layouts of public and private hospitals have also over time created different expectations from patients about heating and cooling systems, patients in public healthcare systems becoming accustomed to naturally ventilated spaces in which the bedside fan is a key tool for cooling, patients in private healthcare systems, reflecting assumptions about hotel-like service, being accustomed to air-conditioned comfort. 
Consequently, both between countries - e.g., the National Health Service in the UK versus the private healthcare system in the USA - and within countries, for example where a public healthcare system is complemented by an optional private healthcare system for those wealthy enough to afford additional subscriptions, variations exist in situated normative expectations, and in turn approaches taken to green hospital design. Knowledges may, therefore, travel relatively easily between hospitals operating within the same type of public or private healthcare system, but may not travel well between heterogeneous contexts. And when combined with the effects of the kinds of regulative influences described above, and the cultural-cognitive logics outlined below, normative effects mean the value of the mobilisation of knowledges apparently begins to reduce as green design approaches are revealed to be more and more specific to a particular institutional context.

In terms of the cultural-cognitive, whilst it would be misleading to over-generalise, interviewees suggested that there is a strong relationship between the regulative dimension and culturalcognitive sense-making frames. Illustrating this idea, the Plumbing Code of Australia, which each state has incorporated into its building codes, sets-out clear guidelines for water preservation, in particular with reference to risk scenarios generated by the national government that predict Australia will face severe water shortages in the future as a result of climate change. Other water-related initiatives in Australia include the National Water Initiative, Water Smart Australia, and the Raising National Water Standards program. The combined effect of codes, various initiatives and the high cost in Australia of water is to institutionalise water preservation as a core part of thinking about building design. Hence in Australia building professionals and speculators expect to invest time and money in a range of design techniques that reduce water 
consumption - it is part of their mental maps of the legitimate way to approach building design even though the Plumbing Code of Australia only mandates a limited number of water saving features such as dual flush toilets. This creates an opportunity to introduce into already normalised discussions of water preservation during the design process techniques that go way beyond regulatory requirements such as grey and black water recycling (recycling water put down the sink and toilet respectively).

In contrast, whilst in the UK codes also mandate water use minimisation, such issues are seen as being of peripheral importance compared with the focus on energy use reduction, in part because of the ease of achieving the relatively lax standards for water reduction, in part because of perceptions (which are not entirely correct) of a less severe threat of drought in the UK, and in part because of relatively low water costs. Hence, expending design effort and cost on water preservation is an unusual and effectively illegitimate practice, with water preservation rarely discussed in the design process; such discussions being seen as abnormal or at best a luxury that most cannot afford because of the financial implications. This limits the ability of designers to introduce innovations such as black and grey water recycling. As two interviewees summarised:

"The architects sit face to face with the client and the client says this is business as usual, and you're saying it's going to cost me $3 \%$ more or $6 \%$ more. How do the architects justify it, how do they explain the value of green building? Regulation is the easiest way, the government made us do it cough up...If it takes any more dollars, anything that's different to normal we have to justify that" (23, Sustainability Manager, Australian professional association) 
"the environmental problems that they face in Australia have pushed buildings to be much more water efficient. And so our latest office in Melbourne, $92 \%$ of the water is recycled on site, they've got black water recycling facilities in an office building in a CBD. You'd never have anything like that in the UK at the moment so that's an example of them really pushing something that we are not pushing over here [in the UK]" (5, UK Sustainability Manager, global property development firm)

This does not mean that strict codes are the only way to generate the cultural-cognitive context for the incorporation of green design features. Building professionals, speculators and, in particular, commercial occupiers in certain sectors increasingly seek to accrue reputational advantages from being associated with or occupying a green building. But, when institutional complexes lead to such reputation driven cultural-cognitive logics dominating design decisions, the types of design chosen tend to be very different when compared with design decisions driven by ways of thinking underlain by regulation or imperatives such as the cost of water (for more on this see Cidell, 2009). In particular, when reputational advantages are sought, visual technological approaches that act as symbols of 'green-ness' are often preferred - things such as wind turbines on the roof of a building. Some interviewees referred to such approaches as the deployment of 'green bling'. As one put it:

"I'm thinking one particular client who I'll decline to name, who said that their philosophy for this particular building was to put PVs [photo voltaics], wind generators, solar hot water and a CHP [combined heat and power] unit on this building. And we said 
hang on a minute why do you need all of those? Why are you engineering such a hefty solution when we can actually get you to similar levels of energy consumption with very little [technological] engineering involved?” (9, Director, UK sustainability consultancy firm)

The incorporation of wind turbines hung between the two towers of the Bahrain World Trade Centre is exemplary of such market-led cultural-cognitive logics, the concern being about the public image of sustainability generated as much as about the reductions in carbon impact achieved.

Table II expands the discussions above and provides further detail of the effects of situated institutions on green design. In summary, as Guy (2006: 653) notes, institutions mean "although two identical buildings... may well appear physically and materially similar, investigations into their respective modes of production and consumption may reveal profoundly different design rationales". For geographers interested in architecture and sustainability, and not just the green design dimensions of sustainability, the institutional perspective developed here is powerful because of its ability reveal the way that combinations of rules, norms and cultural mindsets that have been previously documented in isolation (e.g., Imrie, 2007; Jacobs, 2006; Lees, 2001) together generate situated built forms. And as such, an institutional perspective is not a replacement for existing geographical approaches to studying architecture, but is a way of extending understanding of the multiple interacting forces producing situated designs. And an institutional approach can also provide a way of interpreting the effects of knowledge mobilisation on situated building designs when used to explain why knowledges circulating 
between communities and places experience a journey and process of re-embedding that is far from straightforward, teleological and predictable in terms of effects.

[Insert Table II somewhere here]

\section{Bricolage: the relational assemblage of embedded green design knowledges}

The discussions at the beginning of the paper highlighted how mobile knowledges are twodimensional and relate to: how to use particular techniques to reduce energy and water consumption and waste production; but also how to use these techniques in the situated, institutionally specific context in which the building is being constructed. The analysis in the previous section of the paper reinforces this message and, consequently, it is clear that only if those utilising mobile knowledges understand institutional effects on building design can spatially diffused best practice be used to overcome the challenge of green design. Hence, as one interviewee described, "To put up a sustainable building at a world leading quality you have to work hard, you've got to use your brain, it's not just cookie cutter" (20, Head of sustainability, Australian property development firm ). The need to 'work hard' and 'use your brain' results from the fact that embedded green design knowledges are always needed, such knowledges being bundles of technologies and structural design approaches that solve green design problems and that are deemed legitimate in the situated context generated by the three pillars of institutions. As one interviewee who worked for a global firm described his experience of this need:

"When we first did that [started operating overseas] we looked at a number of ways of doing it and in the end to be honest we did think for a while ok we're going to do everything from the UK...But then we found that there is so much uniqueness in terms of 
how different areas work and the local rules that you've got to align yourselves with that" (10, UK Director of Sustainability, global engineering consultancy).

Another noted how institutional distance means the mobilisation of knowledges between two places located in close physical proximity and sharing the same climatic regimes is not necessarily beneficial:

"There's the thing we refer to it as the North Sea gap, which is a ten year gap between something being done in Holland or somewhere with a perfectly similar climate, no different whatsoever, and it being done here [in the UK]. You couldn't introduce it here until you proved the point that it would work here. And that has been a big problem, we can learn from them. But they have different ways of doing things" (2, Associate, UK sustainability consultancy firm).

As the discussion above of the three pillars of institutions reveals, 'proving the point that it would work here' and transforming a mobile knowledge into something that not only solves a green design challenged but also has institutional legitimacy in a new context is a complex task. For instance, whilst the grey and black water recycling techniques discussed above may primarily face problems at the level of the cultural-cognitive pillar when imported into different institutional contexts, they are also likely to face regulative issues. One interviewee noted that not only had he faced difficulties convincing a developer to pay for water recycling technologies, but health and safety rules specific to the state in question in Australia also effectively prevented the recycling of black water, the rules being designed to ensure all buildings had adequate 
sewerage systems and being originally imposed in the early $20^{\text {th }}$ century when concerns about illness from water born diseases dominated policies relating to water use in buildings. One solution to such difficulties could be, as existing geographical studies of knowledge mobility reveal (McCann, in press; Peck and Theodore, 2001, 2010; Ward, 2006), the modification of knowledge packaged as an exemplary building so as to retro-fit it to a specific institutional context. This could, for example, involve removing the black water recycling facility from a building but leaving other green design features in place. However, interviewees suggested that rather than trying to adapt approaches to green design taken from an ill-fitting iconic building that is deemed illegitimate at the level of two or more of the regulative, normative and culturalcognitive pillars, it is more productive to start with a blank sheet of paper when designing a building. As one interviewee noted:

“the issue that we've got, you know this building is called [building x]. People say let's do a [building $\mathrm{x}$ ] in such and such, well the answer is actually different, you've actually got to go back to your first principles...the solutions that different countries come up with are heavily influenced by what goes on in that country" (19, Australian head of design, global property development firm)

Consequently, what might be more described as a bricolage process that seeks to generate new and embedded green building design knowledges is an important way of utilising mobile knowledges. The concept of bricolage, originally proposed by Lévi-Strauss (1966), captures the way that entrepreneurs use the resources at hand and new combinations of these resources to assemble solutions to everyday problems. In the case of green building design, this means using 
the resources at hand in the shape of awareness of multiple mobile knowledges originating from buildings constructed in several different institutional contexts. This awareness allows the assemblage of an effective approach that will both technically solve the green design challenges faced and have socio-economic legitimacy in the building's situated institutional context; the assemblage being comprised of ideas taken from several iconic buildings that are brought together to generate a new design. As one interviewee summarised, "Where people are doing things en masse like they are in Austria and Germany it would be foolish of us to say well we can't learn anything from that. So we're definitely looking for that kind of stuff...seeing what we can learn from them and bring together in one solution" (9, Director, UK sustainability consultancy firm). Another interviewee, who as well as engaging in professional practice taught at a local university, described how he specifically encouraged his international students to engage in a bricolage process as part of an assignment because of its importance to green design practice. The assignment involves:

“...developing a rating tool for their country for green buildings. They [the students] always astound me each semester by producing rating tools which give different priorities to things. So in some cases water is almost bottom of the list because it's not a priority there. Transport is not seen as essential because there's only one way of getting around Bhutan for examples. Whereas energy in some cases is top of the list and in some it's not important because they get all their power from hydroelectricity" (21, Australian green buildings body representative) 
Which components are borrowed from any particular mobile green building design as part of the bricolage process will be determined by the degree of institutional proximity that exists in relation to an issue. For example, techniques for cooling and lighting may be taken from different buildings, the buildings chosen as sources of inspiration being those constructed in a context where the effects of the three institutional pillars are broadly similar or at least not contradictory.

Rethinking knowledge mobilities: plural geographies and inter-disciplinary relevance

The suggestion that bricolage is essential for developing embedded knowledges relating to green building design draws attention to the way that all cities, regions and countries, regardless of their location in the global north or south, have potential contributions to make to the on-going project of overcoming green design and more widely sustainability challenges, so long as the value of spatial diversity in relational circuits of knowledge mobility is acknowledged.

Reflecting Robinson's $(2005,2011)$ call for a decentring of urban knowledge and theory, the discussion above highlights, then, how institutional topologies of mobility enable the production of new embedded knowledges; topologies being used here to refer to the way each place has and can benefit from a spatially unique set of relational connections to metrically near and far places, these connections acting as sources of diverse green design knowledges that can be folded together into place specific solutions. Consequently, the power of knowledge mobilities is realised not when a single design, technology or policy circulates and gets adapted and reproduced, but when from scratch through bricolage based experimentation the production of multiple and novel local hybrid assemblages occurs; these assemblages bringing together a 
geographically rich array of circulating knowledges. Studying and promoting the intelligent use of topologies of knowledge mobility that are inclusive and diverse rather than exclusive and concentrated in their geography is thus crucial; such topologies being key to making places truly open and fluid relational assemblages (Allen and Cochrane, 2007; Massey, 2005). Existing studies of knowledge mobility do, however, tend to underestimate the importance of the kinds of topologies and the bricolage outlined here, primarily because they have focussed on bi-modal flows of singular policies or designs that get re-embedded through adaptations intended to retrofit them to context-specific institutional regimes. The analysis here provides a corrective to such underestimations, revealing that in studies of knowledge mobilities it is crucial to recognise how multiple mobilised knowledges originating from several geographical sources, as well as already existing local knowledges, can together inform the development of new, plural, 'vernacular' and situated approaches to green design, sustainability generally and any other economic or social challenges. The final section of the paper reflects further on the research agenda this conceptualisation of knowledge mobility presupposes.

From a different perspective, the insights provided here into relational topologies of knowledge mobility are also important because they reveal how economic geographers can more effectively engage with debates about sustainability. Two opportunities stand out in particular. First, the kind of analysis developed here could be used to contribute to work on socio-technical transitions towards sustainability (see Geels, 2004, 2010; Rip and Kemp, 1998; Smith et al., 2005). The key focus in this literature is on the way context-specific regimes and landscapes shape practices such as building design. Regimes are defined as shared rule sets, grammars and socio-cognitive frames about how to approach the challenge of sustainability. Landscapes are 
defined as the background societal logics and technological systems that set the context for any attempt to implement sustainable practices. Context-specific regimes and landscapes are said to influence whether users (who in the case of buildings may be occupiers, building professionals or speculators) respond positively (adopt) or negatively (reject) to sustainability techniques. As Geels (2004) acknowledges, the concepts of regimes and landscapes and understandings of their effects mirror in many ways the concepts and understandings developed in work on institutions, being used to account for the impacts on the adoption of technologies of formal rules (a la regulative institutions), social logics (normative institutions) and cognitive frames (culturalcognitive institutions). Hence the analysis developed here, that is able to account for the effects of institutional diversity on approaches to the sustainability challenge, has potentially much to contribute to work on transitions. Specifically, the discussion here of bricolage suggests that economic geographical studies of mobile knowledges can be used to understand how to produce sustainable technologies and practices tailored to incumbent regimes and landscapes, something that will help drive transitions towards sustainability and avoid negative responses from users. This is a subtly different perspective to the orthodoxy in existing socio-technical transitions literatures in which focus falls on ways of changing existing regimes and landscapes so as to create opportunities for the adoption of new niche sustainability technologies, regardless of the aspirational and potentially hard to achieve nature of such change (Shove and Walker, 2007). This is not to suggest that more widespread transitions in regimes and landscapes should not be the ultimate aim. Rather it is to suggest that adapting sustainability solutions to incumbent regimes and landscapes offers the potential for the relatively quick deployment of solutions, quick at least when compared to the timescales of the kinds of transitions sought by Geels (2004, 2010) and those following in his footsteps. And hence in contrast to Truffer's (2008) suggestion 
that economic geographers might learn about the effects of institutions from those studying the way regimes and landscapes affect transitions to sustainability, the analysis presented here suggests that much might also be learned from economic geographers about regimes and landscapes (sic institutions) and how to respond to them when seeking to invoke sustainability transitions.

Secondly, the perspective developed here might also be used to recast debates in architecture and engineering literatures about the impacts of processes of knowledge mobility on building sustainability, including but not limited to environment related sustainability issues. There is a great deal of sensitivity about the effects of the multiple entangled spatial networks associated with mobile knowledges on the preservation of 'vernacular' (Cole and Lorch, 2003) and plural (Guy and Moore, 2007) architectures and sustainability solutions. The globalisation of standardised parameters of thermal comfort (the temperature range within a building) in ways that ignore situated variations in norms of clothing, comfort and the use of space in buildings in different industries and countries (see Hens, 2009) typifies such arguments. The bricolage process described above questions whether such concerns should lead to the total denial of the value of mobile knowledges. Bricolage allows responsiveness to place-specific material, economic, political and social contexts because of the way multiple overlapping circuits of knowledge can be used to produce new situated and embedded knowledges. And as such, the institutional approach developed here provides a way of overcoming the tendency in some studies to conclude directly from analyses of the spatial heterogeneity of building design and associated sustainability challenges that mobile knowledges are always detrimental. It does this by revealing the way mobile knowledges interact with and get transformed by situated 
institutional contexts and the resultant potential for multiple situated approaches to sustainability in the context of increasingly mobile best practices.

\section{Conclusions}

As noted in the introduction, economic geographers have been slow to deploy their tools to address questions of environmental sustainability. Here, through a focus on the type of institutional hurdles likely to be faced by any attempt to drive sustainability through the mobilisation of knowledge, and analysis of ways of overcoming these hurdles, this tardiness has been shown to be unnecessary. Economic geographers' work has been brought to bear on interdisciplinary research and policy questions about green buildings, in the process opening-up new ways of thinking about transitioning towards sustainability and about the impacts of knowledge mobility on building design. The analysis presented here is also valuable because it simultaneously advances theoretical understanding in economic geography of the regulative, normative and cognitive cultural pillars of institutions and their different but often inter-related effects on the usefulness of mobilised knowledges for addressing context specific (green building design) challenges. In particular, the analysis highlights how interactions between mobilised (green building design) knowledges and situated institutional contexts inspire a bricolage process that draws on geographically diverse relational topologies and allows the generation of new embedded knowledges. This repositions thinking about the re-embedding of mobile policies, models and best practices by emphasising the importance of studying and promoting the generation and intelligent use of plural geographical flows of knowledge, and in particular flows that do not privilege selected cities or global regions as sources of innovation, or assume flows 
provide solutions that can be retro-fitted to new situated contexts. It also suggests that a perspective that views institutional diversity not simply as a barrier to knowledge mobility but as a powerful opportunity to generate plural solutions that can be synthesised and reworked in situated ways is important. Such a perspective places mobile knowledges at the centre of the development of contextualised solutions to societal problems, rather as a threat to local variety and suitability.

In turn, the new perspectives developed in this paper do, however, open-up a number of potentially important questions that have not been addressed here. For example, questions might be asked about whether the benefits of bricolage are eroded by power relations that enable or compel the mobilisation and utilisation of some knowledges and prevent the mobilisation of others; in effect curtailing opportunities for the intelligent use of relational topologies. As Table I reveals, actors have their own motivations, often tied to profitability, meaning mobilised knowledges may not necessarily be optimum sustainability solutions. Asking whether the raw materials provided by mobilised knowledges, and selections made from the plethora of mobilised knowledges when engaging in bricolage, may be overly influenced by the interests of certain parties, whether they be firms, non-governmental organisations or other actors, and the implications of such influence for the appropriateness and effectiveness of solutions to sustainability or other socio-economic challenges thus seems essential. Further questions relate to the spatialities of the institutional topologies of knowledge mobility outlined: where do knowledges currently flow from and to, why are particular spatial connections strong and others weak, and what correctives might be needed to further pluralise the spatiality of knowledge mobility? The discussion here has been somewhat dominated by flows from/to the developed 
world. This raises the question of whether developing-developing, developing-developed flows occur, and if not why not? More widely, questions are also raised about the extent to which new embedded knowledges produced by bricolage are themselves mobilised, and the implications of this in terms of the continuous spatial churning of solutions. Whether knowledge mobilisation could lead to the kinds of institutional (landscape and regime) change that many followers of work on socio-technical transitions believe is needed to deal with challenges such as sustainability is also worth considering. These questions highlight, then, the significant value of the perspective on knowledge mobilities developed here, both for advancing geographical thought and for understanding in the social sciences more widely of the role of mobile knowledges in resolving socio-economic and environmental challenges.

\section{Acknowledgements}

The research reported in this paper was made possible thanks to a British Council funded Researcher Exchange (Reference 2008-09). Earlier versions of the paper were presented at the Universities of Western Sydney, Nottingham, Oxford and Amsterdam. Feedback from audiences at these events helped sharpen the focus of the paper, as did the constructive comments of three anonymous reviewers. The views expressed and any omissions or errors remain, however, the responsibility of the author.

\section{References}


Academy of Sustainable Communities 2007: Mind the Skills Gap. The skills we need for sustainable communities. Leeds: Academy of Sustainable Communities.

Allen, J. and Cochrane, A. 2007: Beyond the territorial fix: regional assemblages, politics and power. Regional Studies 41, 1161-1175.

Amin, A. and Cohendet, P. 2004: Architectures of knowledge: Firms capabilities and communities. Oxford: Oxford University Press.

Amin, A. and Cohendet, P. 1999: Learning and adaptation in decentralised business networks. Environment and Planning D: Society and Space 17, 87-104.

Banister, D., Stead, D., Steen, P., Ǎckerman, J., Dreborg, K., Nijkamp, P. and Schleicher-Tapesser, R. 2000: European transport policy and sustainable mobility. London and New York: Routledge.

Bathelt, H., Malmberg, A. and Maskell, P. 2004: Clusters and knowledge: local buzz, global pipelines and the process of knowledge creation. Progress in Human Geography 28, 31-56.

Bathelt, H. and Schuldt, N. 2007: Between Luminaires and Meat Grinders: International Trade Fairs as Temporary Clusters. Regional Studies 42, 853-868.

Brown, M.A. and Southworth, F. 2008: Mitigating climate change through green buildings and smart growth. Environment and Planning A 40, 653-675.

Bulkeley, H. 2005: Reconfiguring environmental governance: towards a politics of scales and networks. Political geography. 24, 875-902.

Bulkeley, H. 2006: Urban sustainability: learning from best practice? Environment and Planning A 38, $1029-1044$.

Bumpus, A.G. and Liverman, D.M. 2008: Accumulation by decarbonisation and the governance of carbon offsets. Economic Geography 84, 127-155.

City of London 2008: Sustainability Assessment of Global Financial Centres. London: City of London

Cole, R.J. and Lorch, R., editors 2003: Buidlings, culture and Environment. Informing local and global practices. Oxford: Blackwell. 
D'Arcy, E. and Keogh, G. 1997: Towards a property market paradigm of urban change. Environment and Planning A 29, 685-706.

Department of Communities and Local Government 2007: Building a Greener Future: Towards Zero Carbon Development. Department of Communities and Local Government, London

Dicken, P. 2011: Global Shift (6th edition). London: Sage.

Dolowitz, D.P. and Marsh, D. 2000: Learning from abroad: the role of policy transfer in contemporary policy-making. Governance 13, 5-23.

Fairbrass, J. and Jordan, A. 2001: Protecting biodiversity in the European Union: national barriers and European opportunities? Journal of European Public Policy 8, 499-518.

Faulconbridge, J.R. 2006: Stretching tacit knowledge beyond a local fix? Global spaces of learning in advertising professional service firms. Journal of Economic Geography 6, 517-540.

Faulconbridge, J.R. 2009: The regulation of design in architecture firms: embedding and emplacing buildings. Urban Studies 46, 2537-2554.

Faulconbridge, J.R. 2010: Global architects: learning and innovation through communities and constellations of practice. Environment and Planning A 42, 2842-2858.

Faulconbridge, J.R., Beaverstock, J.V., Derudder, B. and Witlox, F. 2009: Corporate Ecologies of Business Travel in Professional Service Firms: Working Towards a Research Agenda. European Urban and Regional Studies 16, 295-308.

Geels, F.W. 2004: From sectoral systems of innovation to socio-technical systems:: Insights about dynamics and change from sociology and institutional theory. Research policy 33, 897-920.

Geels, F.W. 2010: Ontologies, socio-technical transitions (to sustainability), and the multi-level perspective. Research policy 39, 495-510.

Gertler, M. 2010: Rules of the Game: The Place of Institutions in Regional Economic Change. Regional Studies 44, 1-15.

Gertler, M. 2004: Manufacturing culture. Oxford: Oxford University press. 
Gertler, M.S. 2001: Best practice: Geography, learning and the institutional limits to strong convergence. Journal of Economic Geography 1, 5-26.

Gibbs, D. 2006: Prospects for an environmental economic geography: Linking ecological modernization and regulationist approaches. Economic Geography 82, 193-215.

Grabher, G. 2001: Ecologies of creativity: the village, the group and the heterarchic organisation of the British advertising industry. Environment and Planning A 33, 351-374.

Guy, S. 2006: Designing urban knowledge: competing perspectives on energy and buildings. Environment and Planning C: Government \& Policy 24, 645-659.

Guy, S. and Moore, S. 2007: Sustainable Architecture and the Pluralist Imagination. Journal of Architectural Education 60, 15-23.

Hens, H.S.L.C. 2009: Thermal comfort in office buildings: two case studies commented. Building and Environment 44, 1399-1408.

Hitchings, R. 2010: Seasonal climate change and the indoor city worker. Transactions of the Institute of British Geographers 35, 282-298.

Imrie, R. 2007: The interrelationships between building regulations and architects' practices. Environment and Planning B: Planning and Design 34, 925-943.

Jacobs, J.M. 2006: A geography of big things Cultural Geographies 13, 1-27.

King, A. 1984: The bungalow: the production of a global culture: Routledge/Thoemms Press.

Lees, L. 2001: Towards a critical geography of architecture: the case of an Ersatz Colosseum. Ecumene 8, $51-86$.

Levi-Strauss, C. 1966: The savage mind (translated from La pensée sauvage). Chicago: University of Chicago Press.

Lovell, H. and Smith, S.J. 2010: Agencement in housing markets: The case of the UK construction industry. Geoforum 41, 457-468. 
Martin, R. 2000: Institutional approaches in economic geography. In Shappard, E. and Barnes, T.J., editors, A companion to economic geography, Oxford: Blackwell, 77-94.

Massey, D. 2005: For space: London: Sage.

McCann, E.J. 2004: Urban political economy beyond the global city. Urban Studies 41, 2315-2333.

McCann, E.J. 2011: Urban policy mobilities and global circuits of knowledge: Toward a research agenda. Annals of the Association of American Geographers Available at http://www.sfu.ca/ emccann/.

McCann, E. and Ward, K. (Ed.) 2011: Mobile urbanism. Minneaplois \& London: University of Minnesota Press

McNeill, D. 2008: The global architect. Firms, fame and urban form. London \& New York: Routledge.

NHBC Foundation 2009: Zero carbon compendium. Amersham: NHBC Foundation,

Olds, K. 2001: Globalization and urban change. Oxford: Oxford University Press.

Peck, J. and Theodore, N. 2001: Exporting workfare/importing welfare-to-work: exploring the politics of Third Way policy transfer. Political Geography 20, 427-460.

Peck, J. and Theodore, N. 2010: Mobilizing policy: Models, methods, and mutations. Geoforum 41, 169-174.

Pilkington, E. 2010: Empire State Building: Can the tallest be the greenest? The Guardian, 26th July.

Rip, A. and Kemp, R. 1998: Technological change. Human choice and climate change 2, 327-399.

Robinson, J. 2005: Urban geography: world cities, or a world of cities. Progress in Human Geography 29, 757-765.

Robinson, J. 2011: The spaces of circulating knowledge: city strategies and global urban governmentality. In McCann, E. and Ward, K., editors, Mobile urbanism, Minneaplois \& London: University of Minnesota Press, 15-40.

Scott, W.R. 2008: Institutions and organizations. Ideas and interests. London: Sage.

Shove, E. and Walker, G. 2007: Caution! Transitions ahead: politics, practice and transition management. Environment and Planning A 39, 763-770. 
Smith, A., Stirling, A. and Berkhout, F. 2005: The governance of sustainable socio-technical transitions. Research policy 34, 1491-1510.

Storper, M. and Venables, A.J. 2004: Buzz: face-to-face contact and the urban economy. Journal of Economic Geography 4, 351-370.

Truffer, B. 2008: Society, technology, and region: contributions from the social study of technology to economic geography. Environment and Planning A 40, 966-985.

UNEP 2006 Design for sustainability United Nations Environment Programme, New York

Urban Studies (2009) Special issue: Regulating design. Urban Studies 46 (12)

Vallance, P. 2011: Relational and dialectical spaces of knowing: knowledge, practice, and work in economic geography. Environment and Planning A 43, 1098-1117.

van Bueren, E.M. and Priemus, H. 2002: Institutional barriers to sustainable construction. Environment and Planning B 29, 75-86.

Ward, K. 2006: 'Policies in motion', urban management and state restructuring: the trans-local expansion of business improvement districts. International Journal of Urban and Regional Research 30, 54-75.

Whitehead, M. 2007: Spaces of sustainability: geographical perspectives on the sustainable society. London: Routledge.

Willis, C. 1995: Form Follows Finance: Skyscrapers and Skylines in New York and Chicago. Princeton: Princeton Architectural Press.

World Green Building Council 2009 Six continents, one mission. Woodbridge, Ontario: World Green Building Council. 